\title{
Review
}

\section{Arthritis and pain Current approaches in the treatment of arthritic pain}

\author{
Bruce L Kidd, Richard M Langford and Theresa Wodehouse
}

William Harvey Research Institute, Barts and The London, Queen Mary School of Medicine and Dentistry, Charterhouse Square, London EC1M 6BQ, UK

Corresponding author: BL Kidd, b.l.kidd@qmul.ac.uk

Published: 11 June 2007

This article is online at http://arthritis-research.com/content/9/3/214

(c) 2007 BioMed Central Ltd
Arthritis Research \& Therapy 2007, 9:214 (doi:10.1186/ar2147)

\section{Mechanisms of pain Pain classification}

Traditionally, pain has been regarded as being either nociceptive (arising in response to tissue injury) or neuropathic (arising in response to nerve injury). Although this distinction has had some therapeutic utility, it has served to maintain the Cartesian concept of a fixed immutable pain system that faithfully transmits information from a site of injury to pain centres within the brain. Although this is largely true after acute injury, it is clear from epidemiological studies that in the presence of persistent disease a range of additional factors, often unrelated to the musculoskeletal system, serve to modify activity within pain (nociceptive) pathways.

Implicit in recent classification schemes is the notion that acute and chronic pain states are different and that functional changes within the nociceptive system are important in determining the signs and symptoms experienced by individuals with somatic disease [2]. Currently, four different pain states are recognized (Figure 1). The first of these, nociceptive pain, refers to those transient symptoms and signs that arise in response to acute injury and reflects the activation of specialized pain receptors (nociceptors) and corresponding activity in more central pathways. Under these conditions, symptoms broadly reflect the initiating stimulus or injury; treatment at a peripheral level is likely to be successful.

In contrast, neuroplastic pain (also called inflammatory pain) occurs in response to more persistent tissue injury and is the most common pain state associated with musculoskeletal disease [3]. It arises as a result of mediators released from damaged tissues acting to increase the excitability of the nociceptive pathway and has the effect of making everyday

coxibs = cyclooxygenase inhibitors; IL = interleukin; NSAID = non-steroidal anti-inflammatory drug; OA = osteoarthritis; RA = rheumatoid arthritis; $\mathrm{RCT}=$ randomized controlled trial; TENS $=$ transcutaneous electrical nerve stimulation; TNF $=$ tumour necrosis factor. 
Figure 1

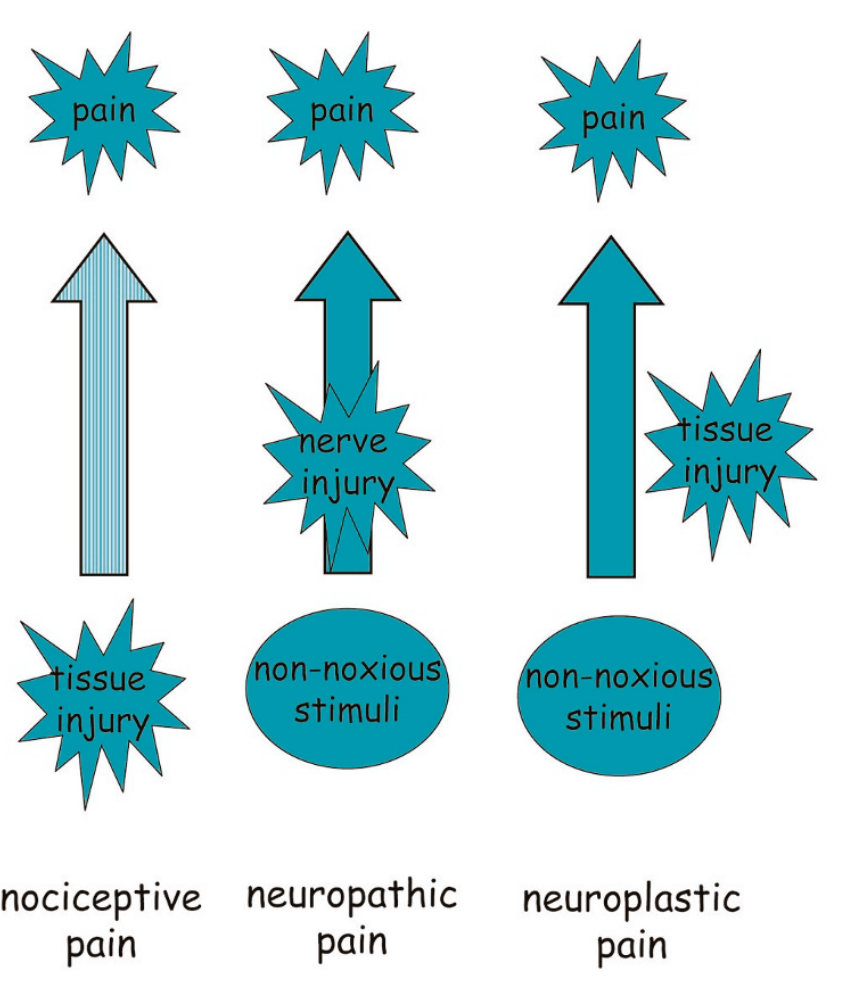

Classification of pain. Nociceptive pain is triggered by tissue injury and activates unmodified nociceptive neurons (light arrow) inducing acute pain. In contrast, normally innocuous stimuli produce pain in neuropathic and neuroplastic conditions in consequence of sensitized nociceptive pathways (dark arrows). Note: Idiopathic pain omitted from figure. (Adapted from [3].)

activities such as standing or walking painful. Effective therapy requires that attention be directed to both the originating injury and those additional factors (see below) that influence nociceptive activity.

Third, neuropathic pain occurs in the presence of nerve injury, as might occur in association with carpal tunnel syndrome or after lumbar disc prolapse. Ectopic expression of ion channels, receptors and related phenomena occur in both injured and neighbouring non-injured neurons, with resultant regional pain hypersensitivity and sensory disturbance.

There is currently debate as to the origins of a fourth pain category, idiopathic pain, which covers such medically unexplained disorders as fibromyalgia syndrome, irritable bowel syndrome and tension headache. In all of these disorders, evidence for peripheral pathology is minimal and symptoms are considered to reflect disordered pain processing at more central levels.

\section{Arthritic pain}

At a local level, mediators released from synovium, bone or other tissues will induce the sensitization of articular pain
Figure 2

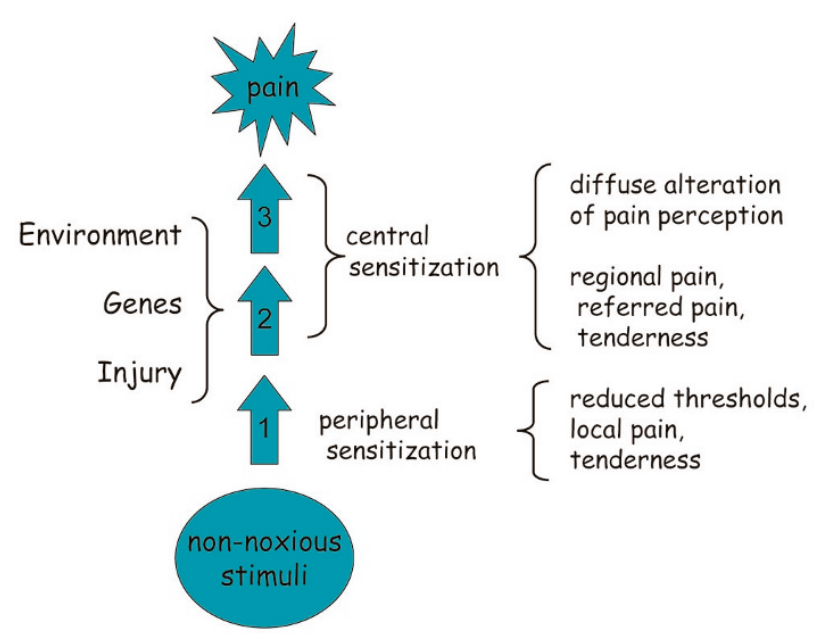

Causes and consequences of neural plasticity. Although tissue injury or inflammation can trigger nociceptor sensitization in peripheral neurons (1), other somatic, psychological and environmental influences are likely to determine the magnitude of any subsequent change as a result of modulation of activity at spinal (2) or cortical (3) levels. (Adapted from [3].)

receptors. The clinical correlate of sensitization at this peripheral level is that musculoskeletal symptoms will be localized, with a relatively close relationship to mechanical stimuli such as walking or standing (Figure 2). Treatment with systemic or topical therapies designed to reduce inflammatory mediators might be expected to have a beneficial effect, which is in accord with clinical experience [4].

In chronic conditions such as osteoarthritis (OA) or rheumatoid arthritis (RA), neural sensitization will not be confined to the periphery. The finding of increased areas of punctate hyperalgesia in patients with RA after topical application of capsaicin is in accord with increased excitability of spinal neurons in this condition [5]. Clinically, this leads to enhanced pain perception at the site of injury, as well as to the development of pain and tenderness in normal tissues both adjacent to and removed from the primary site.

Spinal nociceptive processing in arthritic patients is under the influence of descending inhibitory controls and inputs from other somatic structures [6]. Both previous pain episodes and genetic factors are also likely to influence activity. The multiplicity of mediators involved provides an opportunity for therapeutic intervention, and many of the commonly used therapeutic strategies including acupuncture, transcutaneous electrical nerve stimulation (TENS) and pharmacological agents such as non-steroidal anti-inflammatory drugs (NSAIDs) and the weaker opioid drugs are likely to be exerting an effect at this level.

Psychological and social factors have been shown to be the most important predictors of both the presence and severity 
of pain in a range of disorders including $\mathrm{RA}, \mathrm{OA}$ and persistent low back pain. It seems logical to assume, but remains unproven, that these external factors modulate nociceptive processing at a supraspinal or cortical level [7]. The overall effect is to enhance pain perception and to increase pain reporting and behavioural change, including disability.

Reliance on peripherally or spinally active therapies alone is unlikely to prove successful in those patients with more general symptoms arising from central sensitization. Prostanoid and opioid receptors are constitutively expressed in cortical tissues, and the relevant therapeutic agents are undoubtedly exerting an effect at this level. Nevertheless, additional measures often using non-pharmaceutical approaches, including education and cognitive behavioural therapy, may be required.

Despite the progress that has been made over the past several decades to define key pain processes, the need remains to translate this knowledge into better assessment techniques and more effective pain therapy. Attempts to devise mechanism-based approaches to therapy have met with mixed success, in part as a result of lack of clinical techniques by which to define specific nociceptive processes. Quantitative sensory tests and cortical imaging can be used to quantify central changes associated with articular pathology but are not suitable for more general clinical use. In practical terms, the duration of symptoms is important: the likelihood of a significant central component increases with time. Referred pain and tenderness away from the site of joint pathology are suggestive of a neuroplastic pain state, whereas radicular pain is inevitably associated with neuropathic syndromes.

\section{General approaches to pain management Clinical guidelines}

Published goals for the management of both OA and RA include the prevention or amelioration of joint damage, the prevention of loss of function, and the reduction of pain $[8,9]$. In the absence of complete remission, it is suggested that longitudinal plans for pain management take into account adverse effects and costs, as well as the patient's risk factors, co-morbid conditions and preferences [9].

Guidelines are increasingly used in a range of settings to promote effective multidisciplinary health care (Figure 3). Although clinical guidelines for the management of arthritic pain have been published, their development has been hampered by often insufficient, or frankly contradictory, evidence $[8,9]$. As outlined in the previous section, persistent joint pain arises in response to a range of different factors, and it has proved difficult to adapt evidence obtained from often tightly controlled research trials to more general clinical settings.

A further problem has been the paucity of techniques by which the effects of analgesic intervention can be monitored.
Figure 3

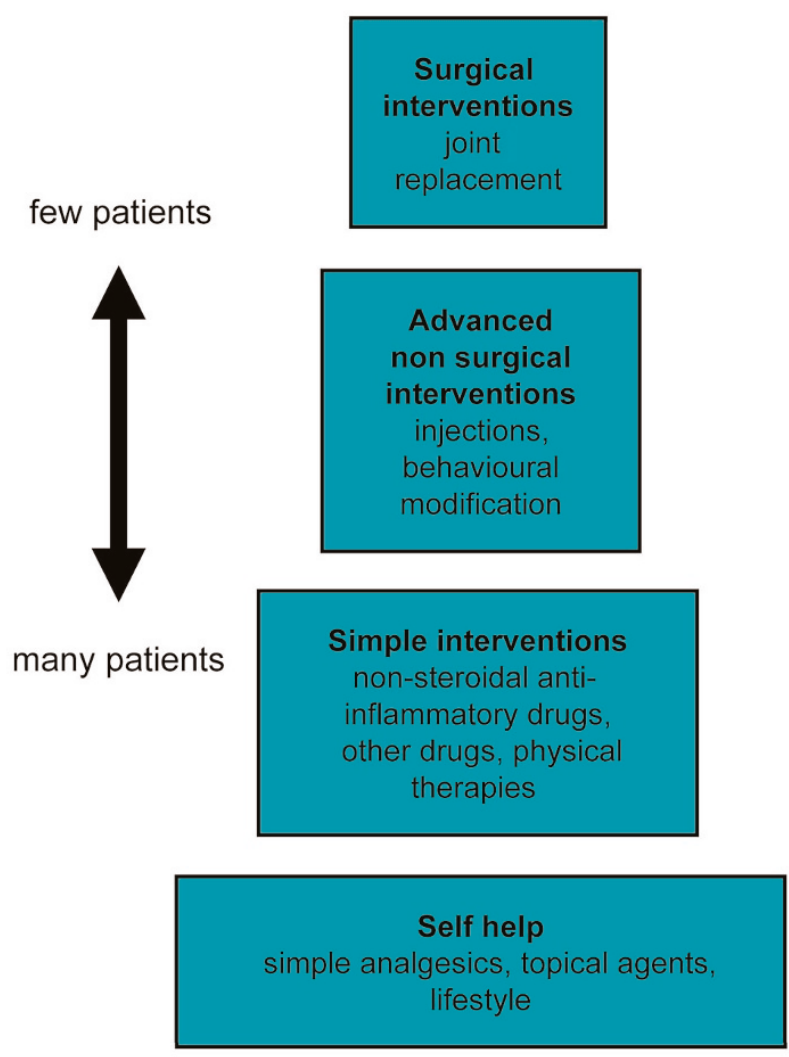

Principles for the management of osteoarthritis: a suggested sequential pyramidal approach to symptom management. (Adapted from [49].)

In practice, although the assessment and integration of available information by an individual health professional might be of high quality, it often proves difficult to systematically quantify the effects of any subsequent intervention. Pain is a subjective experience, and although pain intensity can be monitored with visual analogue scales, other aspects of the pain experience have proved more difficult to capture. Instruments such as the McGill pain questionnaire purport to measure these other domains but have been used mostly for research purposes.

\section{Education and behavioural change}

Patient education has been recommended as a fundamental component of arthritic pain management; however, objective evidence for efficacy remains poor. Systematic reviews report few well-designed randomized controlled trials (RCTs) of education alone [10]. In contrast, more substantial evidence exists for the efficacy of lifestyle modification, particularly exercise and weight reduction [11].

Several systematic reviews evaluating aerobic and strengthening exercises have demonstrated clear benefits with regard 
to both pain reduction and improved function in people with knee and hip OA [12]. Weight loss also reduces OAassociated knee pain in overweight individuals and improves physical activity, especially when combined with regular exercise [13]. Measures that maintain adherence to a regime, such as keeping a personal diary or social support from friends, are thought to improve long-term outcome [11]. Braces and orthotics can also be effective, although evidence for the efficacy of these measures has yet to be fully established in clinical trials.

A small proportion of patients with identifiable musculoskeletal pathology experience extreme and widespread symptoms, often associated with recognizable behavioural changes indicative of a chronic pain syndrome. These individuals may benefit from psychological/cognitive-behavioural therapies as part of a multidisciplinary strategy. Accumulating evidence attests to the efficacy of these approaches in such patients and is reviewed elsewhere [14].

\section{Pharmacological therapies Paracetamol (acetaminophen)}

This drug has been used for over 100 years; however, its mechanism of action remains uncertain [15]. Currently, it has no known endogenous binding sites, but various claims have been made about inhibition of central cyclooxygenase activity, inhibition of $N$-methyl-D-aspartate receptor activity, and stimulation of descending inhibitory pathways [16].

Paracetamol is effective in many arthritic conditions and across all age groups. It has been recommended as the oral analgesic of choice for mild to moderate pain in OA [17] and is generally well tolerated in osteoarthritic patients for periods of up to 12 months [18]. In general, paracetamol has a good tolerability profile and overall safety record, although recently the frequency of use has been reported to be independently associated with a moderate increase in the risk of incident hypertension [19].

\section{Tramadol}

Tramadol is a central-acting oral analgesic that has a unique dual mechanism of action involving both a weak $\mu$-agonist action as well as inhibition of the reuptake of noradrenaline (norepinephrine) and serotonin. It has received widespread approval for use in both moderate and severe pain and has found use as adjunctive therapy for arthritic pain [20]. Tramadol combines favourably with paracetamol and permits a decrease in the use of NSAIDs without compromising analgesia [21]. Use of the drug is limited in a significant proportion of patients as a result of toxicity, with the most commonly reported side effects being dizziness, nausea and constipation [22]. Care should be taken with the concomitant use of serotonin-selective reuptake inhibitors because of potential elevation of basal serotonin levels, with associated risks of seizures and/or serotonin syndrome [23].
Figure 4

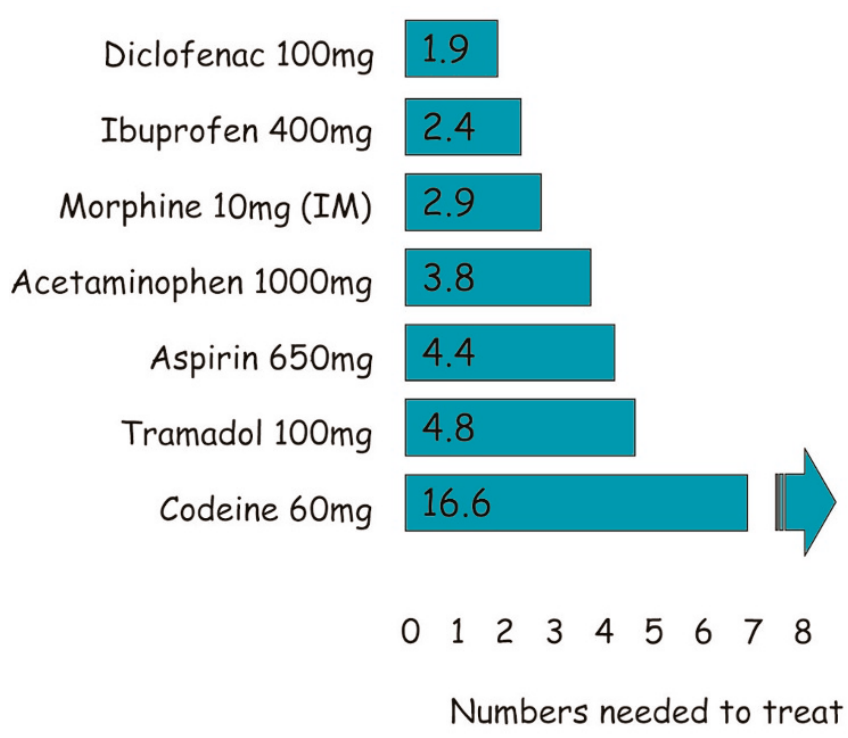

Oxford league table of commonly used analgesics in acute pain. Numbers needed to treat for $50 \%$ pain relief over 4 to 6 hours are shown. Note that no comparable data exist for analgesia for chronic musculoskeletal pain. (Adapted from [50].)

\section{Non-steroidal anti-inflammatory drugs}

The primary anti-inflammatory and antinociceptive effects of NSAIDs have been linked to an inhibitory effect on cyclooxygenase enzymes and a subsequent decrease in inflammatory prostaglandins such as $\mathrm{PGE}_{2}$ and prostacyclin. There is some evidence for a dissociation between the antiinflammatory and antinociceptive effects, in keeping with both peripheral and central sites of action [24].

NSAIDs have been shown to be highly effective for treating acute pain (Figure 4) and remain one of the principal pharmacological agents for treating arthritic pain [25]. Published guidelines and expert opinion are divided over the relative roles of NSAIDs versus paracetamol as first-line analgesic therapy for arthritic conditions. A recent metaanalysis of 15 RCTs involving 5,986 participants concluded that NSAIDs were superior to paracetamol for improving knee and hip pain in OA; however, the effect size for both treatments was modest [26]. NSAIDs are also widely used for symptomatic therapy for RA, although similarly modest effects are observed [27].

Concerns about the toxicity of NSAIDs have become more prominent in recent years. Gastrointestinal events, including perforation, ulceration and bleeding, are well documented and a considerable literature is available for review [28]. Other well recognized problems include oedema and renal insufficiency; however, the development of cyclooxygenase inhibitors (coxibs) has highlighted additional cardiovascular risks associated with these agents. 
International regulatory authorities including the US Food and Drug Administration and the European Medicines Agency have issued warnings on the use of coxibs in patients with increased cardiovascular risk and for long-term use, recommending using the lowest effective dose for the shortest duration. With evidence that both the traditional non-selective NSAIDs and coxibs are associated with cardiovascular adverse events, the broader cardiovascular warning from the US Food and Drug Administration covers the whole class of anti-inflammatory analgesics.

\section{Opioids}

The long-term use of stronger opioids in chronic musculoskeletal conditions remains controversial [29]. Three subclasses of opioids receptor have been described - the $\mu-, \delta$ and $\kappa$-opioid receptors - with a widespread distribution throughout both the central and peripheral nervous systems. Agonists for the $\mu$-receptor display the best analgesic activity but also the highest abuse potential.

There is a relative paucity of evidence to support the isolated use of weaker opioids such as codeine for chronic arthritic pain [30], but these agents are devoid of serious organdamaging effects and when combined with paracetamol may well be clinically safe for long-term therapy [31].

In those arthritic patients for whom NSAIDs are contraindicated or for whom combined therapy is ineffective, the use of stronger opioids may have a limited role [32]. A systematic review of 15 RCTs involving 1,025 patients with chronic non-malignant pain found a mean decrease in pain intensity in most studies of at least $30 \%$, with a comparable effect size in both neuropathic and musculoskeletal pain [29]. Recent developments in oral and transdermal sustainedrelease formulations have increased the safety and utility of strong opioid therapy. Transdermal fentanyl has been shown to be effective in reducing pain scores and improving function in patients with knee and hip OA [33].

In practice, toxicity issues remain a problem; the most commonly reported opioid side effects are constipation, nausea and somnolence [29]. Concerns over abuse potential remain, although patient education and informed consent, exercise, complementary medicine and the use of a controlled-substance agreement increase the likelihood of patient compliance with treatment guidelines, as well as improving functional capacity and quality of life [34].

\section{Antidepressants}

The antinociceptive action of antidepressants is independent of their effect on depression and occurs at lower doses and after a shorter duration of treatment [35]. Tricyclic antidepressants have the best antinociceptive efficacy and act to inhibit uptake of noradrenaline and serotonin, although other actions have been reported.
The main antinociceptive indication for tricyclic antidepressants is for neuropathic pain, although they have beneficial effects in patients with fibromyalgia as well as back pain. More modest effects have been noted in RA [36]. For the most part, these agents remain useful as adjuvant therapy and are not considered front-line analgesic agents in most musculoskeletal disorders.

\section{Anti-cytokine therapies}

Cytokines released from immune cells as part of the inflammatory cascade, including IL-1, IL-8 and TNF- $\alpha$, are hyperalgesic agents as a result of their ability to stimulate the production and release of other pro-inflammatory agents such as bradykinin. Direct effects on primary nociceptors during inflammatory states may also be clinically relevant. Agents that suppress the production or actions of TNF- $\alpha$ have been shown to have potent analgesic activities in clinical trials in patients with various rheumatic diseases, although whether there is a dissociation between the anti-inflammatory and analgesic effects remains to be seen.

\section{Combination analgesics}

The relative failure of single pharmacological therapy to relieve chronic musculoskeletal pain has encouraged the use of combination therapy [37]. Combinations of paracetamol plus codeine are widely used although objective evidence for efficacy is limited by the paucity of clinical trials. Adverse events limit widespread applicability, although titration of the dose against effect is useful in overcoming these problems [38]. More robust evidence supports the use of combinations of paracetamol plus tramadol [37]. Other clinically useful strategies include NSAID plus tramadol or NSAID plus weak opioid, although there are far fewer adequately designed RCTs to provide objective support for these approaches.

\section{Additional approaches}

\section{Topical therapy}

Topical NSAIDs have a proven efficacy across a range of musculoskeletal disorders with fewer side effects than oral therapy [4]. Although used primarily for neuropathic conditions, systemic reviews also support the use of topically applied capsaicin. A limited number of trials report benefit in $\mathrm{OA}$, with around one-third of patients reporting local adverse events, usually burning discomfort at the site of application [39].

\section{Intra-articular injections and other local therapies}

Intra-articular steroid injections are widely used to control symptoms in both $\mathrm{OA}$ and inflammatory conditions. The duration of symptom relief may be relatively short in OA, with effects lasting only a few weeks [40], although longer responses may occur in RA. Concerns over effects on cartilage have been partly allayed by studies suggesting no long-term deleterious events from such therapy [41].

Intra-articular hyaluronic acid (hyluronan) is a high-molecularmass polysaccharide with a multiplicity of biological actions 
Figure 5

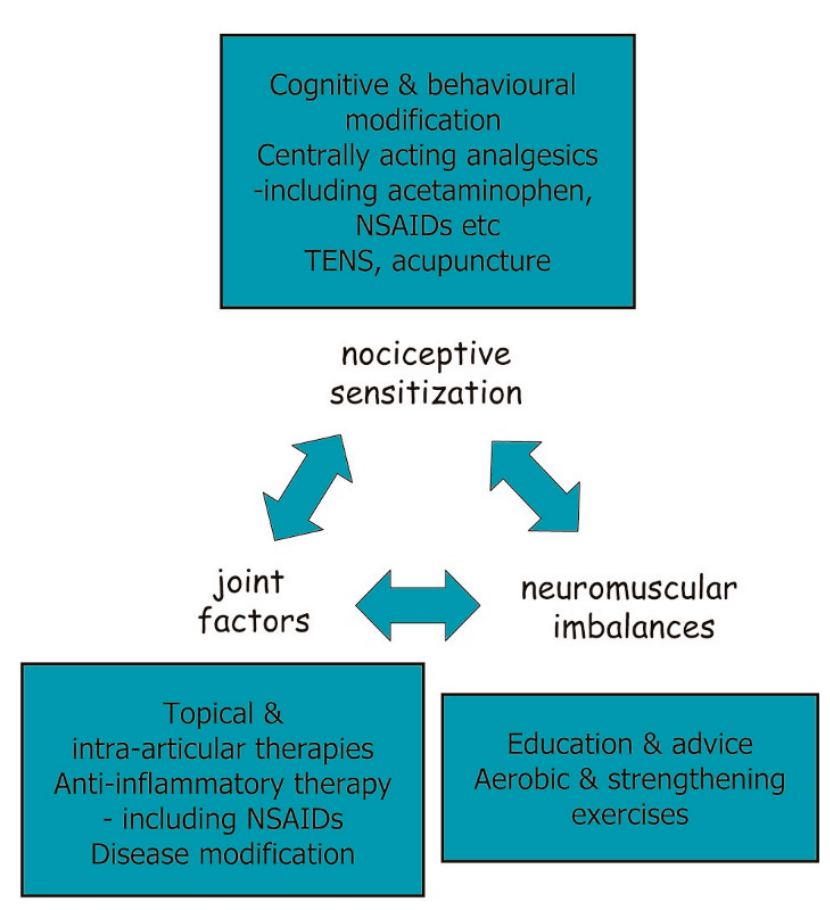

Multimodal therapy for the management of arthritic pain with a mechanism-based approach. Note the lack of a hierarchical system with potential for synergistic interactions between therapeutic options in different boxes.

that has gained favour for symptomatic therapy in OA. Symptomatic benefits may be similar to intra-articular steroids, although the onset of action is delayed, with effects lasting up to 12 months [42]. Glucosamine and chrondroitin sulphate have enjoyed striking popularity for the treatment of $\mathrm{OA}$; they received favourable early reports, but a more recent large-scale trial failed to show benefit over placebo [43].

\section{Acupuncture}

A large proportion of patients with arthritic pain seek help from complementary or alternative sources, with acupuncture being a popular choice. Recent individual RCTs have reported conflicting results [44] in patients with arthritic pain, although a couple of systematic reviews provided generally favourable support with symptomatic benefits over both sham acupuncture and placebo [45]. Overall, acupuncture has a good safety record with few reports of serious adverse effects, and it retains a place in the symptomatic management of patients with arthritis.

\section{Transcutaneous electrical nerve stimulation}

TENS has an established general role in the treatment of chronic pain, although there have been few studies assessing the efficacy of the technique for arthritic pain. Underlying mechanisms of action remain unclear, but in studies of experimental joint inflammation TENS reduces spinal
This review is part of a series on Arthritis and pain edited by Jason McDougall.

Other articles in this series can be found at http://arthritis-research.com/articles/ review-series.asp?series=ar_pain

stimulatory neurotransmitters (glutamate and aspartate) and at the same time activates modulatory opioid, serotonin and/or muscarinic receptors to reduce pain behaviours [46]. In clinical studies, TENS has been found to be as effective as exercise and better than placebo for controlling arthritic pain, although combination approaches produce the most favourable result [47].

\section{Conclusion}

The mechanisms of chronic pain differ from those of acute pain. Although peripheral tissue injury is undoubtedly important for the initiation and maintenance of arthritic pain, more central factors, involving changes to pain pathways, become equally important with time. Strategies for treating arthritic pain need to embrace this reality and will necessarily involve multimodal therapy with both pharmacological and non-pharmacological measures (Figure 5). Despite the theoretical advantages, there is a paucity of objective clinical evidence to show the benefits of using an integrated approach for analgesia in persistent joint pain. Designing and evaluating complex interventions to improve health care pose a considerable challenge and require a substantial investment of time and financial resource [48] but nevertheless remain a key priority for clinical research into musculoskeletal disease.

\section{Competing interests}

RML has received lecture and consultancy fees from Pfizer, GlaxoSmithKline, and performed sponsored research on behalf of Astra Zeneca, Pfizer, Jannsen-Cilag, Johnson and Johnson and Grunenthal. BLK has received lecture and consultancy fees from Pfizer and performed sponsored research on behalf of Astra Zeneca, Napp and Nycomed.

\section{References}

1. Sprangers MA, de Regt EB, Andries F, van Agt HM, Bijl RV, de Boer JB, Foets M, Hoeymans N, Jacobs AE, Kempen Gl, et al:: Which chronic conditions are associated with better or poorer quality of life? J Clin Epidemio/ 2000, 53:895-907.

2. Woolf CJ: Pain: moving from symptom control toward mechanism-specific pharmacologic management. Ann Intern Med 2004, 140:441-451.

3. Kidd BL: The mechanisms of chronic pain. In Pain: Best Practice and Research Compendium. Edited by Breivik H, Shipley M. Edinburgh: Elsevier; 2006:17-24.

4. Mason L, Moore RA, Edwards JE, Derry S, McQuay HJ: Topical NSAIDs for chronic musculoskeletal pain: systematic review and meta-analysis. BMC Musculoskelet Disord 2004, 5:28-36.

5. Morris VH, Cruwys SC, Kidd BL: Characterisation of capsaicininduced mechanical hyperalgesia as a marker for altered nociceptive processing in patients with rheumatoid arthritis. Pain 1997, 71:179-186.

6. Leffler AS, Kosek E, Lerndal T, Nordmark B, Hansson P: 
Somatosensory perception and function of diffuse noxious inhibitory controls (DNIC) in patients suffering from rheumatoid arthritis. Eur J Pain 2002, 6:161-176.

7. Giesecke T, Gracely RH, Grant MA, Nachemson A, Petzke F, Williams DA, Clauw DJ: Evidence of augmented central pain processing in idiopathic chronic low back pain. Arthritis Rheum 2004, 50:613-623.

8. Zhang W, Doherty M, Arden N, Bannwarth B, Bijlsma J, Gunther $\mathrm{KP}$, Hauselmann HJ, Herrero-Beaumont G, Jordan K, Kaklamanis $P$, et al:: EULAR evidence based recommendations for the management of hip osteoarthritis: report of a task force of the EULAR Standing Committee for International Clinical Studies Including Therapeutics (ESCISIT). Ann Rheum Dis 2005, 64: 669-681.

9. American College of Rheumatology Subcommittee on Rheumatoid Arthritis Guidelines: Guidelines for the management of rheumatoid arthritis: 2002 Update. Arthritis Rheum 2002, 46: 328-346.

10. Chard J, Lohmander S, Smith C, Scott D: Osteoarthritis of the knee. Clin Evid 2005, 14:1506-1522.

11. Roddy E, Doherty M: Changing life-styles and osteoarthritis: what is the evidence? Best Pract Res Clin Rheumatol 2006, 20: 81-97.

12. Scott D, Smith C, Lohmander S, Chard J: Osteoarthritis. Clin Evid 2003, 10:1402-1430.

13. Messier SP, Loeser RF, Miller GD, Morgan TM, Rejeski WJ, Sevick MA, Ettinger WH, Pahor M, Williamson JD: Exercise and dietary weight loss in overweight and obese older adults with knee osteoarthritis: the Arthritis, Diet, and Activity Promotion Trial. Arthritis Rheum 2004, 50:1501-1510.

14. Morley S, Eccleston C, Williams A: Systematic review and meta-analysis of randomized controlled trials of cognitive behaviour therapy and behaviour therapy for chronic pain in adults, excluding headache. Pain 1999, 80:1-13.

15. Libert F, Bonnefont J, Bourinet E, Doucet E, Alloui A, Hamon M, Nargeot J, Eschalier A: Acetaminophen: a central analgesic drug that involves a spinaltropisetron-sensitive, non-5- $\mathrm{HT}_{3}$ receptor-mediated effect. Mol Pharmacol 2004, 66:728-734.

16. Graham GG, Scott KF: Mechanism of action of paracetamol. Am J Ther 2005, 12:46-55.

17. Brandt KD: The role of analgesics in the management of osteoarthritis. Am J Ther 2000, 7:75-90.

18. Temple AR, Benson GD, Zinsenheim JR, Schweinle JE: Multicenter, randomized, double-blind, active-controlled, parallelgroup trial of the long-term (6-12 months) safety of acetaminophen in adult patients with osteoarthritis. Clin Ther 2006, 28:222-235

19. Forman JP, Rimm EB, Curhan GC: Frequency of analgesic use and risk of hypertension among men. Arch Intern Med 2007, 167:394-399.

20. Schnitzer TJ, Kamin M, Olson WH: Tramadol allows reduction of naproxen dose among patients with naproxen-responsive osteoarthritis pain: a randomized, double-blind, placebo-controlled study. Arthritis Rheum 1999, 42:1370-1377.

21. Mullican WS, Lacy JR; TRAMAP-ANAG-006 Study Group: Tramadol/acetaminophen combination tablets and codeine/ acetaminophen combination capsules for the management of chronic pain: a comparative trial. Clin Ther 2001, 23:1429-1445.

22. Cepeda MS, Camargo F, Zea C, Valencia L: Tramadol for osteoarthritis: a systematic review and metaanalysis. J Rheumato/ 2007, 34:543-555.

23. Ripple MG, Pestaner JP, Levine BS, Smialek JE: Lethal combination of tramadol and multiple drugs affecting serotonin. $A m ~ J$ Forensic Med Pathol 2000, 21:370-374.

24. Burian M, Geisslinger G: COX-dependent mechanisms involved in the antinociceptive action of NSAIDs at central and peripheral sites. Pharmacol Ther 2005, 107:139-154.

25. Kean WF, Buchanan WW: The use of NSAIDs in rheumatic disorders 2005: a global perspective. Inflammopharmacology 2005, 13:343-370.

26. Towheed TE, Maxwell L, Judd MG, Catton M, Hochberg MC, Wells G: Acetaminophen for osteoarthritis. Cochrane Database Syst Rev 2006, CD004257.

27. Emery $\mathrm{P}$, Suarez-Almazor M: Rheumatoid arthritis. Clin Evid 2003, 9:1349-1371.

28. Laine L: Gastrointestinal effects of NSAIDs and coxibs. J Pain Symptom Manage 2003, 25(2 Suppl):S32-S40.
29. Kalso E, Edwards JE, Moore RA, McQuay HJ: Opioids in chronic non-cancer pain: systematic review of efficacy and safety. Pain 2004, 112:372-380.

30. Peloso PM, Bellamy N, Bensen W, Thompson GT, Harsanyi Z, Babul N, Darke AC: Double blind randomized placebo control trial of controlled release codeine in the treatment of osteoarthritis of the knee or hip. J Rheumatol 2000, 27:764771.

31. Langford RM: Pain management today - what have we learned? Clin Rheumatol 2006, 25:2-8.

32. Caldwell JR, Rapoport RJ, Davis JC, Offenberg HL, Marker HW, Roth SH, Yuan W, Eliot L, Babul N, Lynch PM: Efficacy and safety of a once-daily morphine formulation in chronic, moderate-to-severe osteoarthritis pain: results from a randomized, placebo-controlled, double-blind trial and an open-label extension trial. J Pain Symptom Manage 2002, 23:278-291.

33. Langford R, McKenna F, Ratcliffe S, Vojtassak J, Richarz U: Transdermal fentanyl for improvement of pain and functioning in osteoarthritis: a randomized, placebo-controlled trial. Arthritis Rheum 2006, 54:1829-1837.

34. Goodwin JL, Kraemer JJ, Bajwa ZH: The use of opioids in the treatment of osteoarthritis: when, why, and how? Curr Pain Headache Rep 2005, 9:390-398.

35. McQuay HJ, Moore RA: Antidepressants and chronic pain. $B M J$ 1997, 314:763-764

36. Frank RG, Kashani JH, Parker JC, Beck NC, Brownlee-Duffeck M, Elliott TR, Haut AE, Atwood C, Smith E, Kay DR: Antidepressant analgesia in rheumatoid arthritis. $J$ Rheumatol 1988, 15:16321638 .

37. Combination analgesics. Bandolier Extra 2005 [http://www.jr2. ox.ac.uk/bandolier/Extraforbando/combo.pdf]

38. Kjaersgaard-Andersen $P$, Nafei A, Skov O, Madsen F, Andersen HM, Kroner K, Hvass I, Gjoderum O, Pedersen L, Branebjerg PE: Codeine plus paracetamol versus paracetamol in longer-term treatment of chronic pain due to osteoarthritis of the hip. A randomised, double-blind, multi-centre study. Pain 1990, 43: 309-318.

39. Mason L, Moore RA, Derry S, Edwards JE, McQuay HJ: Systematic review of topical capsaicin for the treatment of chronic pain. BMJ 2004, 328:991-995.

40. Bellamy N, Campbell J, Robinson V, Gee T, Bourne R, Wells G: Intraarticular corticosteroid for treatment of osteoarthritis. Cochrane Database Syst Rev 2005, CD005328.

41. Raynauld JP, Buckland-Wright $C$, Ward R, Choquette D, Haraoui BN, Martel-Pelleteir J: Safety and efficacy of long-term intraarticular steroid injections in osteoarthritis: a randomised trial. Arthritis Rheum 2003, 48:370-377.

42. Lo GH, LaValley M, McAlindon T, Felson DT: Intra-articular hyaluronic acid in treatment of knee osteoarthritis: a metaanalysis. JAMA 2003, 290:3115-3121.

43. Clegg DO, Reda DJ, Harris CL, Klein MA, O'Dell JR, Hooper MM, Bradley JD, Bingham CO, Weisman MH, Jackson CG, et al.: Glucosamine, chondroitin sulfate, and the two in combination for painful knee osteoarthritis. N Engl J Med 2006, 354:795-808.

44. Scharf HP, Mansmann U, Streitberger K, Witte S, Kramer J, Maier C, Trampisch HJ, Victor N: Acupuncture and knee osteoarthritis: a three-armed randomized trial. Ann Intern Med 2006, 145:12-20.

45. Ezzo J, Hadhazy V, Birch S, Lao L, Kaplan G, Hochberg M, Berman B: Acupuncture for osteoarthritis of the knee: a systematic review. Arthritis Rheum 2001, 44:819-825.

46. Sluka KA, Vance CG, Lisi TL: High-frequency, but not low-frequency transcutaneous electrical nerve stimulation reduces aspartate and glutamate release in the spinal cord dorsal horn. J Neurochem 2005, 95:1794-1801.

47. Cheing GL, Hui-Chan CW: Would the addition of TENS to exercise training produce better physical performance outcomes in people with knee osteoarthritis than either intervention alone? Clin Rehab 2004, 18:487-497.

48. Campbell NC, Murray E, Darbyshire J, Emery J, Farmer A, Griffiths $F$, Guthrie B, Lester H, Wilson P, Kinmonth AL: Designing and evaluating complex interventions to improve health care. $B M J$ 2007, 334:455-459.

49. Dieppe PA, Lohmander LS: Pathogenesis and management of pain in osteoarthritis. Lancet 2005, 365:965-973.

50. Oxford league table of analgesics in acute pain [http://www.jr2.ox.ac.uk/bandolier/booth/painpag/Acutrev/ Analgesics/Leagtab.html] 